\title{
The Canmore Declaration: Statement of Principles for Planetary Health
}

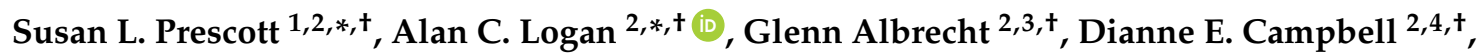 \\ Julian Crane 2,5,, , Ashlee Cunsolo 2,6,+, John W. Holloway 2,7, + (D), Anita L. Kozyrskyj 2,8,, , \\ Christopher A. Lowry 2,9,+ (D), John Penders $2,10,+$, Nicole Redvers $2,11,+$, Harald Renz $2,12,+$, \\ Jakob Stokholm $2,13,+$, Cecilie Svanes ${ }^{2,14,+}$ and Ganesa Wegienka ${ }^{2,15}$, on Behalf of inVIVO \\ Planetary Health, of the Worldwide Universities Network (WUN) ${ }^{\dagger}$
}

1 The ORIGINS Project, Telethon Kids Institute, University of Western Australia, Perth, WA 6009, Australia

2 inVIVO Planetary Health, of the Worldwide Universities Network (WUN), West New York, NJ 10704, USA; glenn.a.albrecht@gmail.com (G.A.); dianne.campbell1@health.nsw.gov.au (D.E.C.); julian.crane@otago.ac.nz (J.C.); ashlee.cunsolo@mun.ca (A.C.); J.W.Holloway@soton.ac.uk (J.W.H.); kozyrsky@ualberta.ca (A.L.K.); christopher.lowry@colorado.edu (C.A.L.), j.penders@maastrichtuniversity.nl (J.P.); dr.redvers@gaiand.com (N.R.); Harald.Renz@uk-gm.de (H.R.); stokholm@copsac.com (J.S.); cecilie.svanes@helse-bergen.no (C.S.); gwegien1@hfhs.org (G.W.) School of Geosciences, The University of Sydney, Sydney, NSW 2006, Australia

Faculty of Medicine and Health, The University of Sydney, NSW 2006, Australia Department of Medicine, University of Otago, Wellington 6242, New Zealand Labrador Institute of Memorial University, Happy Valley-Goose Bay, NL A0P 1E0, Canada Faculty of Medicine, University of Southampton, Southampton SO17 1BJ, UK Department of Pediatrics, University of Alberta, Edmonton, AB T6G 2R3, Canada

Department of Integrative Physiology University of Colorado Boulder, Boulder, CO 80309, USA

Departments of Medical Microbiology, Maastricht University, 6200 MD Maastricht, The Netherlands Arctic Indigenous Wellness Foundation, Yellowknife, NT X1A 2P1, Canada

Institute of Laboratory Medicine, Philipps-University Marburg, 35043 Marburg, Germany

3 COPSAC, Copenhagen Prospective Studies on Asthma in Childhood, Herlev and Gentofte Hospital, University of Copenhagen, 1165 København, Copenhagen, Denmark

14 Centre for International Health, University of Bergen, N-5020 Bergen, Norway

15 Henry Ford Health System, Detroit, MI 48202, USA

* Correspondence: susan.prescott@uwa.edu.au (S.L.P.); aclnd@cfs-fm.org (A.C.L.)

+ Membership of inVIVO Planetary Health, of the Worldwide Universities Network (WUN) is provided in the Acknowledgements.

Received: 26 June 2018; Accepted: 24 July 2018; Published: 26 July 2018

\begin{abstract}
The term planetary health-denoting the interdependence between human health and place at all scales_emerged from the environmental and preventive health movements of the 1970-80s; in 1980, Friends of the Earth expanded the World Health Organization definition of health, stating: "health is a state of complete physical, mental, social and ecological well-being and not merely the absence of disease-personal health involves planetary health". Planetary health is not a new discipline; it is an extension of a concept understood by our ancestors, and remains the vocation of multiple disciplines. Planetary health, inseparably bonded to human health, is formally defined by the inVIVO Planetary Health network as the interdependent vitality of all natural and anthropogenic ecosystems (social, political and otherwise). Here, we provide the historical background and philosophies that have guided the network, and summarize the major themes that emerged at the 7th inVIVO meeting in Canmore, Alberta, Canada. We also provide the Canmore Declaration, a Statement of Principles for Planetary Health. This consensus statement, framed by representative participants, expands upon the 1986 Ottawa Charter for Health Promotion and affirms the urgent need to consider the health of people, places and the planet as indistinguishable.
\end{abstract}


Keywords: planetary health; biodiversity; justice; health equity; cultural competency; Indigenous health; environmental health; ecology; microbiome; DOHaD; health promotion

\section{Introduction}

"Just as peace is not merely the cessation of war, but a positive ideal, so health is not merely the absence of disease"

Sir J. Arthur Thomson, Profess r of Natural History, University of Aberdeen, 1921 [1].

In April 2018, international experts convened in Canmore, Alberta, Canada, to discuss the interdependence of personal, public, and planetary health. Participants with varied professional and disciplinary backgrounds presented research and perspectives on some of the most pressing issues of our time. These include, but were not limited to, infectious and non-communicable diseases, biodiversity losses, climate change, environmental degradation, socioeconomic inequality and poverty, health disparities, the dominance and marketing of ultra-processed foods, mental health and its biopsychosocial underpinnings, changing psychological relationships to the land/natural environment, marginalization of the voices and knowledges of minorities and Indigenous people, antimicrobial resistance, and disturbances brought about by rapid urbanization.

The meeting was hosted by inVIVO Planetary Health, an international research cooperative originating from the World Universities Network; the group, formed in 2012, has a multidisciplinary, multidimensional agenda that has drawn together a broad range of expertise aimed at better understanding the causes, consequences and potential solutions related to the grand challenges of our time. The cornerstone of inVIVO is scientific discovery and illumination of the ways in which the total lived experience (emotional experiences and physical/sensory exposures, both positive and negative) and environmental quality can manifest in immune and physiological parameters of health, disease and 'dis-ease'. In this quest, researchers from biological and medical sciences are better informed by perspectives of expert scholars from broader domains, including, but not limited to, experts in public health, ecology, political/social/environmental sciences, anthropology, philosophy, geography, spirituality, human culture, history/tradition, architecture, arts, ethics, and Indigenous governance and sciences. With this foundation, inVIVO is committed to an integrative approach to the process of discovery, one that treasures civility, respect, reciprocity, responsibility, relationships, optimism, and the fulfillment of human potential-as captured in concepts of the 'symbiocene'; an anticipated epoch in which mutualism will be considered imperative [2,3].

Here, we provide the historical background, which has guided the group to date and summarizes the major themes that emerged at the 7th inVIVO meeting. In doing so, we provide the Canmore Declaration, as a Statement of Principles for Planetary Health (Box 1). This consensus statement, framed by representative participants, expands upon the 1986 Ottawa Charter for Health Promotion [4], and aligns with all aspects of the United Nations (UN) 2030 Agenda for Sustainable Development. It underscores the interconnectivity of all 17 UN Sustainable Development Goals (SDGs) [5] and affirms the urgent need to consider the health of person, place and planet as indistinguishable.

Given that:

I. health is wellness

II. high-level wellness of humankind is a primary goal

III. planetary health is vital to and inextricably interlinked with high-level wellness

IV. and humankind must advocate for planetary health, the Canmore Declaration underscores that the critical problems of our time are non-linear and adisciplinary; as such they will require creative solutions with input from diverse perspectives. The starting point for any organization dedicated to health (as opposed to a specific disease or disorder) is contemplation of the word 
health and its meaning. Whether at scales of the individual, the community, the nation or the planet-whether human, plant or non-human animal life-the questions that must be posed are, "what is health?" and "how does health differ from disease?"

\section{Box 1. Statement of Planetary Health Principles-21st Century Agenda for Global Health.}

1. The sustainable vitality of all systems: Planetary health, inseparably bonded to human health, is defined as the interdependent vitality of all natural and anthropogenic ecosystems; this vitality includes the biologically defined ecosystems (at micro, meso and macro scales) that favor biodiversity; it includes the more broadly defined human-constructed social, political, and economic ecosystems that favor health equity and the opportunity to strive for high-level wellness; this definition also includes the business ecosystems that influence sustainable and health-promoting local and global commerce.

2. Values and purpose: Attitudes, values and behaviors, and relationships sit at the heart of reaching planetary health goals; that is, human vitality (wellness) depends intimately on planetary vitality that in turn depends on humankind, on human kindness, empathy, mutualism, responsibility, and reciprocity at the individual, community, societal and global levels; thus, achieving planetary health must be a product of the interconnected systems of life and the approach to living (lifestyle) — the bios and biosis, respectively.

3. Integration and unity: Planetary health is rooted in ancestral concepts of the unity of life; the complexity of the challenges we face demands integrationist approaches; responsibility for planetary health requires us to relinquish conventional professional, societal, and cultural partitions and to develop contextual coalitions based both on science and broader cultural narratives.

4. Narrative health: Promoting awareness and discourse toward solutions (including those emerging from science) demands a narrative-based process that includes traditional knowledge and sciences and an understanding of the power of language; in healthcare, this underscores a role for researchers, clinicians, public health physicians and health promotion professionals in engaging patients and the community-at-large (and their influencers, policy makers and political representatives) to underscore the importance of the earth's natural systems and biodiversity to human health and well-being.

5. Planetary consciousness: Planetary health requires commitment to self-awareness, cultural competency, and critical consciousness; to reduce the ways in which social, economic and political systems oppress groups and communities in different (and unequal) ways; to challenge contextual power hierarchies that block health equity; and to correct sources of misinformation that stand in the way of well-established personal, public and planetary health practices

6. Nature relatedness: We should educate on the importance of emotional connections to the land, to nature and its biodiversity; consider the psychological asset of nature-relatedness in clinical settings and beyond; encourage further research directed at understanding how mental and emotional relationships with place and planet are developed, and the biopsychosocial implications of experience (or lack, thereof) with nature.

7. Biopsychosocial interdependence: In the context of personalized/precision medicine, where possible we should promote understanding of our dependence on the natural environment around us (flora, fauna and our physical world) and intimately part of us (the human microbiome); use opportunities to illustrate and educate on how physiology (in health and disease) and dysbiosis (as a measurable microbial construct, and a metaphor from its Latin roots 'life in distress') can be linked through ecosystems operating from the micro to macro scales (e.g., misuse of antimicrobials, low-grade inflammation and/or the microbiome).

8. Advocacy: We should advocate for greater inclusion of the planetary health perspective in the training of all healthcare professionals; advocate for early-life education in sciences that 1) illustrate the interconnectivity of human life with the Earth's biodiversity and its natural systems; and 2) illustrate how individual wellness is predicated on our way of living with other humans, and other forms of life. Such discourse should be encouraged and included in the education of caring and teaching professionals (and widely throughout society), such that individuals will strive to lead by example, to reduce primacy and encourage unity.

9. Countering elitism, social dominance and marginalization: Planetary health requires greater awareness of the impact of authoritarianism, and strong advocacy against collective narcissism, hubris, and social dominance orientation, factors that otherwise reduce empathy, marginalize out-group voices and impede the World Health Organization's stated goals for global health promotion; research across all domains should occur with meaningful community engagement and partnerships that carefully consider the motivation and the beneficiaries of the research agenda.

10. Personal commitment to shaping new normative behaviors: We should strive to live by example: in clinical/academic/public settings and beyond we should endeavor to include the principles and practices of a planetary health lifestyle; in daily behavior, we should aim to be part of the solution, not the problem; remain committed to a planetary peace agenda; encourage mutualism, empathy and community cohesion; and underscore that aggression, conflict and violence are destructive to person, place and planet. 


\section{Defining Health, Wellness}

"HEALTH: (i). The state of an animal or living body, in which the parts are sound, well-organized and disposed, and in which they all perform freely their natural functions; in this state the animal feels no pain; this word is also applied to plants. (ii). Sound state of the mind; natural vigor of faculties. (iii). Sound state of the mind in a moral sense; goodness."

Health as defined in Scientific Dictionary, 1863 [6]

Health is, of course, associated with the absence of disease and pain, yet it has long-since been defined to include positive terms such as 'vigor' and freedom to perform natural functions; indeed, after World War II, the World Health Organization included 'complete physical, mental and social well-being' in its Constitutional definition of health. There is little doubt, however, that over the last 50 years the focus and interpretation of health has been, understandably, heavily oriented toward disease eradication. On this score, particularly with regard to infectious disease and the armamentarium of biomedical research and development, there have been remarkable returns on investment. Immunization and antimicrobial therapies have reduced the morbidity and mortality due to infectious pathogens in the population, though pathogens remain a significant threat to the health of civilization. However, as the global burden of disease has shifted toward chronic, non-communicable diseases (NCDs), a greater need to understand the contribution of the environment and planetary ecosystems (as it relates to total, positive health and wellness) has emerged.

In a 1959 landmark paper, biostatistician and public health physician Halbert L. Dunn conceptualized the idea of 'high-level wellness' for humankind and civilization at-large (Box 2); Dunn called for greater research investments to be directed toward an understanding of the social, biochemical, physiological, and psychological pathways to 'peak wellness' (which he defined largely as 'vitality' and the full potential of an individual) (Box 2). Writing in the American Journal of Public Health, Dunn maintained that "wellness is not just a single amorphous condition ... but is rather a fascinating and ever-changing panorama of life itself, inviting exploration of its every dimension" [7]. In this context, he presciently included risks to wellness being population pressures, rising rates of mental and functional illnesses, and the rapid speed of technological growth (particularly communications). Moreover, he stated: "it is probably a fallacy for us to assume, as so many of us have done, that an expansion in scientific knowledge can indefinitely counterbalance the rapidly dwindling natural resources of the globe" [7]. In other words, Dunn was acutely aware, even in 1959, that the ability to obtain high-level wellness at individual and civilization-wide scales, was predicated on the health of the planet.

Dunn's context for high-level wellness was beyond even national boundaries; in the era of rapid change, no longer could health be viewed as exclusively a local phenomenon: "The effects of these [environmental/social] changes ripple outward to all parts of the physical environment, affecting the entire ecology on which man is dependent, and also penetrating into the deepest recesses of his inner world" [8]. The search for high-level wellness in life (Greek, bios) cannot be separated from our individual and collective mode of living (Greek, biosis) or lifestyle; to understand such connections, Dunn advocated for educational efforts to "develop interest in biology on a vast scale, so that it would become of major interest to all. This would mean acquiring a deep interest in life -in the life process itself" [9]. Related to this, Dunn emphasized a need to understand how human attitudes to other forms of life (and the natural environment in general) are formed.

In his writings, Dunn underscored that pathways to individual and societal high-level wellness include a sense of purpose and opportunities for creative expression. He also discussed barriers to high-level wellness: most notably authoritarianism, clinging to dogma, myopic and uncritical allegiance to politicians/priests/pundits, and the inability to adjust beliefs and communication based on evolving knowledge (Box 3). Indeed, Dunn maintained that global wellness in the modern era is predicated upon teaching children critical appraisal skills early in life, and the ability to listen to opposing views while 'searching for points of mutual agreement'. Rather than focusing on what individuals were 'against', Dunn proposed a 'universal philosophy of living' that all humans would be 
'for': "a philosophy which will permeate the minds and hearts ... a philosophy which men and women of good will, regardless of race, creed and nationality, can be for. A unifying type of philosophy which can be embraced and lived by all, within their own cultural background" [10].

Box 2. High-Level Wellness.

"Wellness is conceptualized as dynamic-a condition of change in which the individual moves forward, climbing toward a
higher potential of functioning. High-level wellness for the individual is defined as an integrated method of functioning
which is oriented toward maximizing the potential of which the individual is capable, within the environment where [they]
are functioning. This definition does not imply that there is an optimum level of wellness, but rather that wellness is a
direction in progress toward an ever-higher potential of functioning ... high-level wellness, therefore, involves (1) direction
in progress forward and upward towards a higher potential of functioning, (2) an open-ended and ever-expanding tomorrow
with its challenge to live at a fuller potential, and (3) the integration of the whole being of the total individual-[their] body,
mind, and spirit-in the functioning process ... high-level wellness is also applicable to organization, to the nation, and to
[humankind] as a whole" Halbert L. Dunn, MD, Ph.D. Canadian Journal of Public Health, 1959 [11]

More than a half-century on, Dunn's writings on the topic of high-level wellness remain relevant and of major importance to global health challenges; whilst he called for greater research emphasis on the physiological underpinnings of health, he also outlined the impediments to its study and actualization and described the potential risks of what we would now recognize as "silo" mentality in health and medical research. Dunn concluded that professional territorialism, particularly in science, medicine and the study of the human 'spirit' (our own inner world by which we conceptualize and interpret our perceptions of the outer world) - and the ways in which Western culture has divided the spirit and the body - was a barrier to health research: "The fragmentation of [humans] into areas over which various groups struggle to maintain their jurisdiction appears to be nonsensical since it tends to defeat the purposes of each group ... harmony between jurisdictions can come to pass only when each special interest group realizes that it does not and cannot have monopoly over a particular area ... [humans are] a physical, mental, and spiritual unity - a unity which is constantly undergoing a process of growth and adjustment within a continually changing physical, biological, social and cultural environment". Similarly, Indigenous communities have long recognized the interconnectedness of physical, mental and spiritual health. For example, the Maori concept of 'te whare tapa whä' - the four cornerstones (or sides) health model; physical, spiritual, family and mental health [12].

In sum, the membership of inVIVO shares the views presented by Dunn; health is 'vitality'. At the personal level, vitality is described by researchers (and measured by various scales, including the vitality subscales of the SF-36 or Profile of Mood States) as 'approaching life with excitement and energy, feeling vigorous and enthused; living life as an adventure; feeling alive and activated; zest for life'. Vitality is emerging as a reliable marker of both physical and psychological well-being [13-17]; it appears to be both a cause and consequence of a healthy diet, exercise, social support and other lifestyle habits [18-20]. Moreover, outdoor experience and exposure to natural environments has been linked with personal vitality and increasingly to protection from or modification of disease [21]. 
Box 3. Advocacy, Authoritarianism and Planetary Health.

\begin{abstract}
"If we believe in it [high-level wellness], if we are living it every day of our lives, we must speak out on its behalf. We must resist the mechanisms used to distort the truth and to warp our minds into submission. We must strive to open clogged channels of communication. We must strike out ... at distortion, prejudice and rule by fear". [10]
\end{abstract}

Dunn underscored that authoritarianism is a primary blockade to global wellness; he encouraged greater inclusion of political science in wellness discourse, as well as the study of leadership styles, and broader awareness of the propagandistic misuse of scientific findings (Box 3). While the threat of political authoritarianism to public health is well known [22,23], authoritarianism and social dominance orientation are not exclusive to politics; they can be found in many contemporary social structures, including those associated with westernized medicine [24] and science (which can subsequently determine topics 'worthy' of study and selectively influence 'health' policy) [25]. Contemporary research supports Dunn's contention that individual (and in-group) authoritarianism stands in the way of the collective action that otherwise promotes high-level wellness in the form of social rights-based movements (civil, gender, environmental, etc.) [26].

As we segue to health at the planetary scale, it is worth noting that, beyond the individual, vitality is oft-used in the context of community and ecological health; researchers commonly refer to (and develop indicators of) the 'vitality' of public communities, forest ecosystems, soils, bodies of water, fisheries, and the landscape in general. So, too, vitality of the 'business ecosystem', 'academic faculty', 'organizational structure', 'democracy', etc., is commonly used within the writings of experts in occupational research, political science and economics [27-30]. Hence, the vitality of ecosystems (as well as the vitality of particular species within them)-and our own vitality-is the common language of global health and high-level 'wellness'.

\title{
3. Planetary Health
}

"Even with all our medical technologies, we cannot have well humans on a sick planet. Planetary health is essential for the well-being of every living creature. Future healthcare professionals must envisage their role within this larger context"

Thomas Berry, 1992 [31]

The idea that human health is firmly attached to the vitality of the larger environment is part of the traditional knowledge that has been passed on by Indigenous cultures since time immemorial; it is experience-based, not merely theoretical knowledge. Moreover, the idea that health is not merely the absence of disease, but rather, a larger state of global wellness, has also been discussed throughout recorded history. Thus, we underscore that any proposition that might present 'planetary health' (the connections between human wellness and the health of ecosystems of scale) as a new idea or conception is, indeed, an absurdity. There has already been grotesque levels of appropriation of Indigenous knowledge, and any 'claims' of newness (or ahistorical assertions that marginalize ancestrally-rooted traditional perspectives) are not only at odds with the WHO mandate for global health [32], but will only serve to magnify an unhealthy 'in-group' dominance and undermine the opportunities for high-level wellness.

With due respect for the longevity and origins of the notion, we turn toward the specific term 'planetary health' in contemporary discourse. Over the last four decades it has been used to signify the interdependence of human health with that of the Earth's natural ecosystems. The term re-emerged from the environmental movement of the 1970s; for example, in 1980, the group Friends of the Earth shifted the World Health Organization's decades-old definition of health to include an ecosystems context, moving the health definition beyond individuals, communities and borders; "Health is a state of complete physical, mental, social and ecological well-being and not merely the absence of disease-personal health involves planetary health" [33]. In 1986, the landmark Ottawa Charter for Health Promotion underscored a 'socioecological approach to health'; the Charter erased the lines between states of health at various scales: 
"The overall guiding principle for the world, nations, regions and communities alike is the need to encourage reciprocal maintenance-to take care of each other, our communities and our natural environment. The conservation of natural resources throughout the world should be emphasized as a global priority" [4]. This remains a challenge in an age of increasing narcissism and declining empathy [34]; that 'winner take all' attitudes remain dominant and encouraged further underscores the vital need for a significant shift in value systems.

The Charter reflected the formalization of a growing sentiment within public health and the healing professions, one that demanded greater attention to holistic views of well-being, systems approaches to health (biological and otherwise), as well as the perspective of the total lived environment (at local and global scales). Throughout the 1990s, allied health professionals began using the term planetary health to underscore that the health of the earth's natural systems has clinical relevancy, especially in prevention $[35,36]$. The term was, of course, also used by environmental scientists; for example, marine biologist Sylvia Earle, Chief Scientist of the National Oceanic and Atmospheric Administration (NOAA) in the early 1990s, stated quite correctly that she was "charged with looking after planetary health" [37].

This history of the term planetary health at once reflects the multidisciplinary nature of use, and also highlights the way in which the term cut through silos and unified individuals from seemingly disparate branches of science and healthcare. What has changed since the early origins of the term, at least in meaning, is only the increasing seriousness and urgency of the adisciplinary topic of planetary health; never before has there been a greater need for multidisciplinary collaboration. It is becoming increasingly clear that large-scale biodiversity losses, climate change, the global crisis of non-communicable diseases, psychological distress (especially in youth), incivility/conflict, isolation/loneliness (especially among older adults), prevalence of ultra-processed foods, unnecessary prescription use/polypharmacy, antimicrobial resistance, environmental degradation and grotesque social/health inequalities are interconnected problems that cannot be sealed or solved within traditional academic silos.

In 2015, the Lancet Commission on Planetary Health included 'civilization' in their definition of planetary health, defining it as 'the health of human civilization and the state of the natural systems on which it depends'. From its Latin roots civitas and civilis, civilization is related to citizenship, townships and city-states. Marquis de Mirabeau (who first used the term 'civilization' in 1756) and other Enlightenment writers envisioned a universal humanity that emphasized moderation, self-regulation, humane laws, a high level of purpose, decency in conduct, and limitations on war [38]. However, for many Indigenous peoples and colonized groups globally, the word "civilization" has been brandished as a means to invade their spaces, destroy their connectivity to nature and ancestral protection of biodiversity, and threaten their existence, culture, and territorial sovereignty [39]. Thus, the inclusion of the word civilization forces the question of "what kind of civilization and according to whom?", and a need to determine the quantifiable markers that truly capture the sustainable health and vitality of any human community.

The linkages between the rise and fall of human civilizations vis à vis natural systems (and environmental degradation) have been witnessed, retrospectively, over the millennia; yet, it still remains difficult for humans to see these connections in a prospective way. Scientific tools have helped populations to visualize the threats posed by climate change, environmental degradation and global biodiversity losses - and the pathways which lead to NCDs-but massive challenges remain, especially with regard to human behavior change. Thus, our view of citizenship in the 21st century must place a cognitive-behavioral 'concern for future consequences' as priority in a 'humane society'. As Jonas Salk stated, citizenship in the new era means wanting "those who follow us to look back on us as having been wise ancestors, good ancestors" [40]. 
As the term planetary health moves into the lexicon of mainstream science and medicine, there are also grand opportunities; indeed, the opportunity to break down silos has never been better. It is increasingly clear that the historical territorialism in the turf-protected branches of science and medicine is an arbitrary and artificial 'ism' that impedes progress. Scientific advances allow clinicians, policymakers and the public-at-large to see how threats to the Earth's natural systems and biodiversity losses (and related problems mentioned above) are manifesting in NCDs, the immune system, the human-associated microbiome, mental health, and other objectively-measurable, health-relevant endpoints. While there are fundamental differences in emphasis, overlapping groups such as One Health, EcoHealth, the Planetary Health Alliance, and other planetary health organizations (and representative journals such as Lancet Planetary Health) are working toward the same holistic and interdisciplinary goals of safeguarding heath at the human-animal-environment interface [41].

The inVIVO group shares the same tangible goals of these and other global networks: to support evidence-informed policy and practice which tackles some of the most pressing health concerns of our time.

One of the goals of inVIVO-through research and discourse-is to personalize planetary health for individuals, healthcare providers and policymakers, and provide a greater understanding of the ways in which 'systems' (social, political, economic, cultural) are interconnected and of relevance to biological systems at the individual, community and global levels (See Box 4). Low-grade inflammation (immune responses in general) and the microbiome (even though it is still in its scientific infancy) represent points of entry for discourse concerning the ways in which lifestyle-and the social, political and marketing factors that influence lifestyle-can manifest in the biology of health. For example, it is already possible to trace the policies and practices that promote the marketing of westernized diets, ultra-processed foods/soft drinks and fast-food (that is, dietary patterns that are at odds with high-level wellness at personal, public and planetary scales) to low-grade inflammation, widespread microbial perturbation, and environmental degradation [42-45]. Moreover, it is also possible to determine how negative outcomes associated with such policies and practices are disproportionately shouldered by disadvantaged individuals and communities [46].

These biopsychosocial interactions underscore the critical intersection between mechanistic studies and social sciences. Advances in metagenomics, proteomics, metabolomics, and systems biology are providing new ways of evaluating the biological impact of total environmental exposures-the 'meta-exposome' defined as the total environmental exposures affecting all living systems [47]. This multi-layered approach, now facilitated by integrative bioinformatics and high-performance visualization engines, allows examination of complex exposures at the both individual and population levels, and interactions between these. In this way, we can better examine the bidirectional effect of the environment on human subjects and, conversely, the human influence on all living systems and their genomes [47]. As well as defining the adverse exposures eroding health, this will illuminate exposures that promote resiliency over the life course, to pave the way for health promotion and disease prevention. 
Box 4. Narrative-Based Planetary Health.

\begin{abstract}
"For we dream in narrative, daydream in narrative, remember, anticipate, hope, despair, believe, doubt, plan, revise, criticize, construct, gossip, learn, hate and love by narrative. In order to really live, we make up stories about ourselves and others, about the personal as well as the social past and future" [48].
\end{abstract}

Professor Barbara Hardy, University of London. 1968

Stories and storytelling are central to the human experience. Narrative-based medicine is a burgeoning movement within medical training and clinical care; it places emphasis on the 'story' of the patient and their symptoms and concerns in the context of their total lived experience. It also includes the physician's own stories-inclusive of their personality features, values and collected experiences-which interact with the patient; ideas concerning causation and pathways to management-especially concerning complex, chronic diseases and the pursuit of wellness-become their own story and form the basis of communication. The importance of 'the story' and the benefits of narrative-based medicine in clinical care (especially regarding effective communication, empathy-building, deeper understanding, increasing awareness, diminishing fear, pathways to change) are described within expert reviews [49,50]. Furthermore, psychodrama - a form of experiential therapy that uses active and creative approaches (in particular, guided drama and role playing) - may also illuminate the importance of personal stories vis à vis planetary health [51].

The principles of narrative medicine need not be constrained to the clinic; the health and wellness of communities, places and the planet itself also demands a narrative approach. The story of planetary health (or the voice of the planet) can be made audible through a deeper understanding of our biopsychosocial relationship to the Earth. Concepts such as 'nature relatedness', 'sense of place', 'topophilia', etc., help to provide a narrative surrounding the development of individual and community-level emotional connections to the land [52], and 'ecological grief' provides a story concerning the consequences of destroying those bonds [53].

Narrative-based planetary health will, as stated by Harvard psychiatrist John E. Mack (1929-2004), allow us to "tell unpleasant or unwelcome truths about ourselves ... to explore our relationship with the Earth and understand how and why we have created institutions that are so destructive to it.

"Developing the new [relational psychology of the Earth], it must, by virtue of the very nature of the task, be a psychology that includes a powerful spiritual element. This will mean, for example, a reanimation of the forests and of nature, which we have so systematically and proudly denuded of their spiritual meaning ... by and large we in the West have rejected the language and experience of the sacred, the divine, and the animation of nature. Our psychology is predominantly a psychology of mechanisms, parts, and linear relationships. We have grown suspicious of experiences, no matter how powerful". [54]

Discovery and solutions-oriented research concerning these and other grand challenges facing humanity (and the threats faced by all species on Earth) is essential to the progression of public health [55] (Box 5); however, the complexity of discourse transcends any particular discipline, and necessitates an understanding of traditional cultures, politics, global marketing, and the psychology of behavior and individual differences [38,56]. As stated by scholars Louise Potvin and Catherine M. Jones: "There is a tendency to ignore that scientific facts alone cannot drive action; it is the normative lens through which scientifically established facts are read that ultimately dictates public action" [57]. It is our opinion that within clinical, academic and other settings, the narrative of planetary health requires a looking glass so that an individual can see the Earth's natural systems (and human-built social/political/economic systems that influence those natural systems) within themselves. 
Box 5. Planetary Health Basics.

\begin{abstract}
As highlighted in the Lancet Rockefeller Report [53], human progress in expansion of life expectancy, global reductions in poverty, and curbing of child mortality has been impressive; however, coincident with these gains have been massive increases in resource consumption and exploitation of the environment. Planetary health is, according to the Report, predicated upon nutritious food supplies (less food waste and dietary patterns that decrease environmental pressures), clean water (used with less wastefulness), nutrient-dense soils (curbing soil degradation), maintenance of forests (curbing deforestation), family planning, city planning, and overall better governance (with an aim toward local, national and global policies that reduce environmental damage and promote health) [58]. Planetary health is at the nexus of urgent global concerns; worldwide, close to a billion people experience chronic hunger (with many more experiencing micronutrient deficiencies), and billions still lack safe drinking water, sanitation and/or household energy [59,60]; these pressing concerns-basic matters of health—are already being compounded in some regions by climate change [61].
\end{abstract}

\title{
4. inVIVO Planetary Health, 2018 Conference
}

The headline theme of the 2018 meeting was "Transforming Life, Unifying Personal, Public and Planetary Health". Set against the awe-inspiring, species-rich, fecund ecosystem of the Canadian Rockies, our agenda underscored the critical links between nature, biodiversity and human health, enriched and informed by stories from Inuit and other First Peoples' communities. We addressed not only the physical impact of environmental degradation, but the psychological and existential distress experienced by individuals and communities when their 'place' and 'purpose' are eroded by environmental damage through the concept of 'solastalgia' coined by eco-philosopher Dr Glenn Albrecht [62], who set forth the philosophical framework for our meeting. While effects of 'ecological grief' may be more evident in communities with closer relationships with natural environments, as emphasized by Dr Ashlee Cunsolo, the effects of climate change, environmental degradation, and macroscale biodiversity losses are increasingly affecting every community [53]. As expressed by Indigenous cultures for centuries "Human health and planetary health are the same thing ... to harm the Earth is to harm the self" [63] (Figure 1).

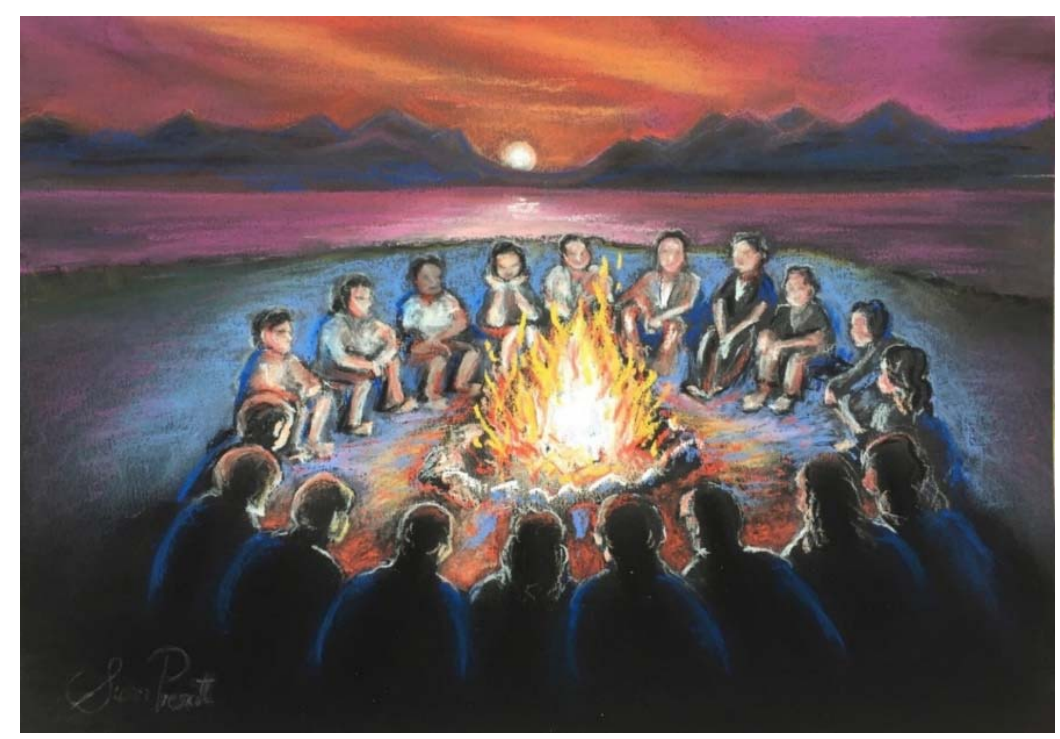

Figure 1. The Canmore Declaration: for personal and planetary health in every community—promoting the interdependent vitality in all natural and anthropogenic ecosystems. Improving the health of all systems depends on: mutualistic values; planetary consciousness; advocacy; unity of purpose; recognition of biopsychosocial interdependence; emotional bonds between people and the land; efforts to counter elitism, social dominance and marginalization; meaningful cross-sectoral and cross-cultural narrative; self-awareness; and a personal commitment to shaping new normative attitudes and behaviors. 
Extending this, concepts of 'dysbiotic drift' [64] underscore how rapid urbanization and modern lifestyle patterns are also reflected on the microscale, and how disruption of microbial diversity, essential to all aspects of physical and mental health, is implicated in the epidemic rise of inflammatory NCDs [42]. Thus, microbiome science allowed us to begin to draw more direct lines between personal and planetary health, and provided the context for unifying conversations between researchers from biological, psychological, environmental and social sciences with a holistic and integrated perspective.

This framework also provided the basis for discussing how specific facets of the modern environment contribute to dysbiosis (in both the microbiological definition and the Greek etymological root $=$ Life in Distress) and inflammation. This included the increasing burden of modern dietary patterns with ultra-processed food, escalating technology culture, sedentary indoor behavior, air and water contamination, large-scale use of antimicrobial products (including pharmaceuticals and household cleaning products), alcohol, tobacco, excessive noise and light pollution, stress (physical and psychological), electromagnetic radiation [65,66], screen-time, sleep disruption and many other adverse exposures that were not present in pre-industrial environments. These social 'vectors' of dysbiosis demonstrate how the risk of NCDs is actually transmissible through social and economic systems and through intergeneration epigenetic effects $[67,68]$ with implications for environmental justice [69]. Our discussions underscored that solutions to the global health crisis will ultimately depend on upstream 'life course' approaches, which recognize that a significant proportion of disease risk is programmed early in life [70]. Moreover, it is our position that dysbiotic drift disproportionally affects the health of disadvantaged populations, addressing these issues is a matter of both social and ecological justice.

We made clear that solutions must not only address the burden of 'excess', but also recognize the dual burden incurred by the 'loss' of protective aspects of ancestral environments, and consider attempts to restore some aspects of the latter. These facets of 'loss' extend from the obvious physical loss (of biodiversity, species, local foods and produce) to the loss of community (of language, tradition, and stories) and the far less tangible aspects of loss (of value systems, privacy and solitude, peace, respect, spirituality, compassion, awe and wonder). Efforts to address this are essential to restore our sense of purpose, place and identity, and ultimately for all aspects of our personal and societal health.

Through our collaborations, there is a growing network of prevention-based intervention cohorts aiming to improve health outcomes within an ecological framework: exploring the wider factors that enhance resilience, such as building nature relatedness [71,72], interpersonal relationships, purpose, mindfulness [73], and positive emotions [74] and increasing the amount and quality of our sleep. This will determine whether these 'upstream' approaches to wellness behavior will have flow-on effects on the 'usual' risk targets (such as poor nutrition, physical inactivity, stress, and substance abuse) by influencing these core behaviors through better relationships with self, community and the environment. It is our conjecture that in addition to contributing to our knowledge base, that community cohorts, especially those focused on young families, could be part of the solutions in every community towards nourishing individuals and whole communities. In essence, cohort studies represent a pathway for global change to begin locally, through interconnected grass-roots strategies.

Inspiring examples included the work of indigenous physician Dr Nicole Redvers in conjunction with the Artic Indigenous Wellness Foundation; recipient of the \$1 million Artic Inspiration Prize, Dr Redvers and her team work toward revitalizing community health with language, culture, traditional foods and practices [75]. There were numerous other examples of ecological solutions with multi-dimensional benefits, including restoring beneficial microbes to improve soil health and crop yields, detoxifying environmental pollutants, and even buffering against colony collapse disorder in bees by protecting against pesticide immunotoxicity [76]. When applied to low-income communities, such as those in sub-Saharan Africa, ecological strategies to food production are showing community benefits not only for health but also for employment, training and women's empowerment [77]. In Hong Kong, relatively simple nature play programs in young children [72] are already showing benefits, not only for social and emotional outcomes and nature connectedness, but also for physical 
activity and healthier eating habits and behaviors. The nation-wide benefits of nature-based programs have been illustrated in Finland $[78,79]$ where there are now plans for multi-city day-care programs to promote: (1) more fruits and vegetables and less meat; (2) less food waste; and (3) more nature contact in children as a partly-controlled study that will also examine the impact on skin microbiomes and diverse health outcomes.

Our meeting had a strong focus on positive emotional assets for long-term health and resilience, including evidence of anti-inflammatory effects [74] and other biological benefits of interventions such as mindfulness training [73]. Interventions to promote positive emotional assets in children are showing benefits for global mental health outcomes [80]. This is of increasing importance in the face of the current mental health crisis (another consequence of dysbiotic drift), with significant increases in psychological distress now affecting children and youth.

We had comprehensive discussions on the complex biological pathways that may promote mental well-being, including the apparent benefits of contact with environmental microbiota [81] and how this may be modulated through contact with natural environments [82] and/or through microbial interventions [83], such as probiotics in animal models [84] and in humans [85]. As a major determinant of the gut microbiome, there was a strong focus on the adverse ecological effects of ultra-processed foods [86] and modern dietary patterns, and how these foods may alter the gut microbiome as a pathway to their adverse effects on metabolism and inflammation [46]. Conversely, we explored the multiple health benefits and anti-inflammatory effects of traditional dietary patterns (including the Mediterranean diet), which have recently demonstrated possible benefits for mood and mental health [87]. Examples of efforts to restore traditional sustainable foods and understanding the impact of food transitions on Indigenous populations $[88,89]$ were discussed, including the sense of hope and community empowerment that these programs bring. In this, we strive to support the "reanimation of the forests and of nature, which we have so systematically and proudly denuded of their spiritual meaning" [54].

Taking many lessons from First Peoples, inVIVO Planetary Health is committed to concepts of mutualism in addressing global health and environmental challenges, recognizing that creative, nonlinear solutions will require diverse integrative perspectives. Our discussions affirmed our commitment to breaking down the artificial boundaries between disciplines that can serve as barriers to progress. While our role is in gathering the evidence required for creating pathways to change, it is equally directed at the advocacy required to get there. We affirmed our goal of continuing to contribute to the global health narrative, by creating a forum for researchers, educators and advocates from any field to join a shared conversation. The voices of early career researchers featured prominently in our program, many already internationally recognized, because we hope to encourage cross-sectoral links for a new generation of care takers, to help build the values and vision for generations to follow.

\section{The Canmore Declaration}

Among the many health charters and declarations, the World Health Organization's 1986 Ottawa Charter for Health Promotion remains a timeless framework for the building of a healthier world with greater equity and socioeconomically just systems. Of course the world has changed dramatically since 1986, especially with regard to telecommunications, automation, and global marketing; however, these disruptive forces were not unanticipated, and indeed the deeply-transformative potential of the internet and occupation-displacing robotics were already in widespread discussion by the mid-1980s [90-92]. The framers of the Ottawa Charter set up a progressive, foundational agenda for health promotion, which is no less relevant in the era of high-technology.

Briefly, the Ottawa Charter underscored that health promotion should be oriented to larger aspects of wellness, including consideration of the upstream drivers (societal systems, communities and organizations) that work toward (or against) the adoption of healthy lifestyles by individuals. The Charter set forth basic prerequisites for health, including peace, shelter, education, food, income, a stable ecosystem, sustainable resources, social justice, and equity. The framers moved beyond local boundaries and included a planetary, socioecological approach to health: "Caring, holism and ecology 
are essential issues... the inextricable links between people and their environment constitute the basis for a socioecological approach to health. The overall guiding principle for the world, nations, regions and communities alike is the need to encourage reciprocal maintenance-to take care of each other, our communities and our natural environment" [4].

The Charter underscores that the pathway to fulfilling prerequisites for health (and the broader aspects of human potential, and human well-being) demand that individuals, groups and organizations (i). Advocate (advocacy for health-promoting initiatives including political advocacy), (ii). Enable (facilitate equitable opportunity for healthy choices, education/skills, access to information), and (iii). Mediate (health promotion does not "belong" to one particular entity or group; however, in the pursuit of health, professionals in the health sector have a major responsibility to mediate between differing interests in society). The Charter settles on five action areas: build healthy public policy; create supportive environments; strengthen community action; develop personal skills; and re-orient health care services toward prevention of illness and promotion of well-being.

The Ottawa Charter is the template for the promotion of global wellness, and we encourage readers to review the concise document. The Ottawa Charter's primary tenets remain timeless, and its exhaustive coverage of the systems that determine health promotion have only magnified its saliency in the midst of a crisis of NCDs, gross health inequalities, and environmental degradation. Here, we pledge support for the Ottawa Charter and include our own Statement of Principles concerning what has since been termed planetary health (see Box 1).

\title{
6. Conclusions
}

In April 2018, the inVIVO Planetary Health network convened in Canmore, Alberta, Canada. Planetary health, inseparably bonded to human health, was formally defined by the network as the interdependent vitality of all natural and human-generated ecosystems (social, political, and otherwise). The discussions underscored that the complex, non-linear problems that threaten health at levels of person, place, and planet are adisciplinary; input from multiple disciplines will allow us to pose the right questions, to set a planetary health research agenda that can further illustrate and inform on the direct and indirect pathways between the high-level wellness of humankind and the vitality of the Earth's natural systems.

Planetary health requires scientific discovery and illumination of ways in which the total lived experience (mental/emotional experiences and physical/sensory exposures, both positive and negative) and environmental quality, can manifest in immune and other physiological parameters of health, disease and 'dis-ease'. It is our contention that planetary health requires an understanding of traditional and place-based knowledges and sciences and cultural competencies. Planetary health is not a new idea or concept; it is a concept well-understood by our ancestors-to damage the Earth is to damage the self. The inVIVO Planetary Health collaborative is committed to an integrative approach to the process of discovery, one that treasures civility, respect, reciprocity, responsibility, relationships, optimism, and the fulfillment of human potential.

\begin{abstract}
"The challenge posed by the concept of high-level wellness is how to achieve its ends within everyday living and for [humankind] as a whole. The challenge must be met both by individuals and by society within its various groups, ideologies, races, religions, and cultural patterns. Self-assurance will be needed to meet this challenge. We must have the courage to change ourselves when this is called for and to trust ourselves and our fellow [humans] ... to the dictum from the Greeks, "know thyself", we must mature so that we can add to it, "trust thyself"."
\end{abstract}

Halbert L. Dunn, Canadian Journal of Public Health, 1959 [4].

Author Contributions: All authors contributed to the inVIVO Planetary Health conference discussions that formed the conceptual basis of this paper. A.C.L. and S.L.P. undertook Writing-Original Draft Preparation. G.A., D.E.C., J.C., A.C., J.W.H., A.L.K., C.A.L., J.P., N.R., H.R., J.S., C.S. and G.W. were all involved in Writing-Review and Editing. 
Funding: This work received no external funding.

Acknowledgments: We acknowledge the contribution and support of all inVIVO Planetary Health members who attended and participated in the conference which formed the basis of this declaration.

Conflicts of Interest: S.L.P. reports the following: Scientific Advisory Board and speaker fees from Danone Nutricia, Schiphol, Netherlands and Nestlé Nutrition Institute, Lausanne, Switzerland; consultancy fees from Bayer Dietary Supplements Division, Whippany, NJ, USA; speakers fees from Health World Inc., Queensland, Australia; research grants from the National Health and Medical Research Council (NHMRC) of Australia. A.C.L. has received consultancy fees from Genuine Health, Toronto, Canada and speaker fees from Health World Inc., Queensland, Australia. C.A.L. serves on the Scientific Advisory Board of Immodulon Therapeutics, Ltd. D.E.C. has received travel support to attend DBV Technology investigators meetings, and funding from NHMRC, AIFA, Nestlé Nutrition and Abbott all directed to her institution. H.R. has received a grant from the German Research Foundation and the German Center for Lung Research and payment for lectures from Allergopharma, Novartis, Thermo Fisher, Danone, Mead Johnson Nutritional, and Bencard and has received payment for research and development projects from Hycor, Mead Johnson, and Beckman Coulter. G.W. received grant funding from the National Institutes of Health (USA). G.A., J.C., A.C., J.W.H., A.L.K., J.P., N.R., J.S. and C.S., declare no conflicts of interests.

\section{References}

1. Thomson, J.A. The Control of Life; Henry Holt ad Co.: New York, NY, USA, 1921; p. 170.

2. Albrecht, G. Ecopsychology in the symbiocene. Ecopsychology 2014, 6, 58-59. [CrossRef]

3. Albrecht, G.A. Exiting the anthropocene and entering the symbiocene. Minding Nat. 2016, 2, 12-16.

4. World Health Organization. Ottawa Charter for Health Promotion. Available online: http://www.who.int/ healthpromotion/conferences/previous/ottawa/en/ (accessed on 25 July 2018).

5. United Nations 2030 Agenda for Sustainable Development: 17 Sustainable Development Goals (SDG). Available online: https://www.un.org/sustainabledevelopment/sustainable-development-goals/ (accessed on 25 July 2018).

6. Ogilvie, J. The Imperial Dictionary: English, Technological, and Scientific; Blackie and Son: Glasgow, UK, 1863; Volume 1, p. 900.

7. Dunn, H.L. High-level wellness for man and society. Am. J. Public Health Nations Health 1959, 49, 786-792. [CrossRef] [PubMed]

8. Dunn, H. High-level wellness in the world of today. J. Am. Osteopath. Assoc. 1962, 61, 978-987. [PubMed]

9. Dunn, H.L. High-Level Wellness; Slack Publishing: Thorofare, NJ, USA, 1977; p. 189.

10. Dunn, H.L. Your World and Mine-Essays on Human Relations; Exposition Press: New York, NY, USA, 1956; p. 92.

11. Dunn, H.L. What High-Level Wellness means. Can. J. Public Health 1959, 50, 447-457. [PubMed]

12. Durie, M.H. A Maori perspective of health. Soc. Sci. Med. 1985, 20, 483-486. [CrossRef]

13. Kubzansky, L.D.; Thurston, R.C. Emotional vitality and incident coronary heart disease: Benefits of healthy psychological functioning. Arch. Gen. Psychiatry 2007, 64, 1393-1401. [CrossRef] [PubMed]

14. Lambiase, M.J.; Kubzansky, L.D.; Thurston, R.C. Positive psychological health and stroke risk: The benefits of emotional vitality. Health Psychol. 2015, 34, 1043-1046. [CrossRef] [PubMed]

15. Boehm, J.K.; Trudel-Fitzgerald, C.; Kivimaki, M.; Kubzansky, L.D. The prospective association between positive psychological well-being and diabetes. Health Psychol. 2015, 34, 1013-1021. [CrossRef] [PubMed]

16. Penninx, B.W.; Guralnik, J.M.; Bandeen-Roche, K.; Kasper, J.D.; Simonsick, E.M.; Ferrucci, L.; Fried, L.P. The protective effect of emotional vitality on adverse health outcomes in disabled older women. J. Am. Geriatr.Soc. 2000, 48, 1359-1366. [CrossRef] [PubMed]

17. Rouse, P.C.; Veldhuijzen Van Zanten, J.J.; Ntoumanis, N.; Metsios, G.S.; Yu, C.A.; Kitas, G.D.; Duda, J.L. Measuring the positive psychological well-being of people with rheumatoid arthritis: A cross-sectional validation of the subjective vitality scale. Arthritis Res. Ther. 2015, 17, 312. [CrossRef] [PubMed]

18. Schmitt, A.B.F.; Den Hartog, D.N. Feeling vital after a good night's sleep: The interplay of energetic. resources and self-efficacy for daily proactivity. J. Occup. Health Psychol. 2017, 22, 443-454. [CrossRef] [PubMed]

19. Dempsey, P.C.; Howard, B.J.; Lynch, B.M.; Owen, N.; Dunstan, D.W. Associations of television viewing time with adults' well-being and vitality. Prev. Med. 2014, 69, 69-74. [CrossRef] [PubMed]

20. Ryan, R.M.; Bernstein, J.H. Vitality. In Character Strengths and Virtues; Peterson, C., Seligman, M., Eds.; Oxford University Press: New York, NY, USA, 2004; pp. 273-289. 
21. Ryan, R.; Weinstein, N.; Bernstein, J.; Brown, K.W.; Mistretta, L.; Gagne, M. Vitalizing effects of being outdoors and in nature. J. Environ. Psychol. 2010, 30, 159-168. [CrossRef]

22. McKee, M. Health professionals must uphold truth and human rights. Eur. J. Public Health 2017, $27,6-7$. [CrossRef] [PubMed]

23. Greer, S.L. Medicine, public health and the populist radical right. J. R. Soc. Med. 2017, 110, 305-308. [CrossRef] [PubMed]

24. Prescott, S.L.; Logan, A.C. From Authoritarianism to Advocacy: Lifestyle-Driven, Socially-Transmitted Conditions Require a Transformation in Medical Training and Practice. Challenges 2018, 9, 10. [CrossRef]

25. Lemaitre, B. Science, narcissism and the quest for visibility. FEBS J. 2017, 284, 875-882. [CrossRef] [PubMed]

26. Weiner, E.; Federico, C.M. Authoritarianism, institutional confidence, and willingness to engage in collective action: A multinational analysis. Pers. Soc. Psychol. Bull. 2017, 43, 392-406. [CrossRef] [PubMed]

27. Shah, D.T.; Williams, V.N.; Thorndyke, L.E.; Marsh, E.E.; Sonnino, R.E.; Block, S.M.; Viggiano, T.R. Restoring faculty vitality in academic medicine when burnout threatens. Acad. Med. 2018, 93, 979-984. [CrossRef] [PubMed]

28. Reeves, M.; Levin, S.; Ueda, D. THE BIG IDEA The Biology of Corporate Survival. Harv. Bus. Rev. 2016, 94, $46-55$.

29. Tummers, L.; Kruyen, P.M.; Vijverberg, D.M.; Voesenek, T.J. Connecting HRM and change management: The importance of proactivity and vitality. J. Organ. Change Manag. 2015, 28, 627-640. [CrossRef]

30. Dalton, R.J. Citizenship norms and the expansion of political participation. Polit. Stud. 2008, 56, 76-98. [CrossRef]

31. Berry, T. Healing the Injuries we have inflicted on our planet. Health Prog. 1992, 73, 60-63. [PubMed]

32. WHO Traditional Medicine Strategy: 2014-2023. Available online: http://apps.who.int/iris/bitstream/ 10665/92455/1/9789241506090_eng.pdf (accessed on 22 June 2017).

33. Anonymous. Conservation Society Notes: Health Care. Alternatives 1980, 9, 2.

34. Twenge, J.M. Overwhelming evidence for generation me. Emerg. Adulthood 2013, 1, 21-26. [CrossRef]

35. Stohl, C. Planetary health: Are you part of the solution? Beginnings 1991, 11, 6.

36. Parker, J. Toward a Nursing Ethic for Sustainable Planetary Health. In Proceedings of the First National Nursing the Environment Conference, Melbourne, VIC, Australia, 25-26 March 1993; pp. 87-91.

37. Earle, S.A. Sea Change: A Message of the Ocean. Available online: https://tos.org/oceanography/assets/ docs/10-3_duff.pdf (accessed on 24 July 2018).

38. Prescott, S.L.; Logan, A.C. Larger than Life: Injecting Hope into the Planetary Health Paradigm. Challenges 2018, 9, 13. [CrossRef]

39. We are Survival, the Global Movement for Tribal Peoples' Rights. Available online: https://www. survivalinternational.org (accessed on 24 July 2018).

40. Locke, R. All the problems of man are not going to be solved in a laboratory. Advocate 1984, 164, $1 \mathrm{~B}$.

41. Lerner, H.; Berg, C. A Comparison of Three Holistic Approaches to Health: One Health, EcoHealth, and Planetary Health. Front. Vet. Sci. 2017, 4, 163. [CrossRef] [PubMed]

42. Prescott, S.L.; Wegienka, G.; Logan, A.C.; Katz, D.L. Dysbiotic drift and biopsychosocial medicine: How the microbiome links personal, public and planetary health. Biopsychosoc. Med. 2018, 12, 7. [CrossRef] [PubMed]

43. Donovan, S.M. Introduction to the special focus issue on the impact of diet on gut microbiota composition and function and future opportunities for nutritional modulation of the gut microbiome to improve human health. Gut Microbes 2017, 8, 75-81. [CrossRef] [PubMed]

44. Mayer, E.A.; Hsiao, E.Y. The Gut and Its Microbiome as Related to Central Nervous System Functioning and Psychological Well-being: Introduction to the Special Issue of Psychosomatic Medicine. Psychosom. Med. 2017, 79, 844-846. [CrossRef] [PubMed]

45. Dore, J.; Multon, M.C.; Behier, J.M. Participants of Giens Xxxii RTN The human gut microbiome as source of innovation for health: Which physiological and therapeutic outcomes could we expect? Therapie 2017, 72, 21-38. [CrossRef] [PubMed]

46. Prescott, S.L.; Logan, A.C. Each meal matters in the exposome: Biological and community considerations in fast-food-socioeconomic associations. Econ. Hum. Biol. 2017, 27, 328-335. [CrossRef] [PubMed]

47. Renz, H.; Holt, P.G.; Inouye, M.; Logan, A.C.; Prescott, S.L.; Sly, P.D. An exposome perspective: Early-life events and immune development in a changing world. J. Allergy Clin. Immunol. 2017, 140, 24-40. [CrossRef] [PubMed] 
48. Hardy, B. Towards a Poetics of Fiction: An Approach through Narrative. Novel 1968, 2, 5-14. [CrossRef]

49. Zaharias, G. What is narrative-based medicine? Narrative-based medicine 1. Can. Fam. Physician 2018, 64, 176-180. [PubMed]

50. Rosti, G. Role of narrative-based medicine in proper patient assessment. Support. Care Cancer 2017, 25, 3-6. [CrossRef] [PubMed]

51. Bacallao, M.; Smokowski, P.R. Navigating the Web of Worries: Using Psychodrama Techniques to Help Latino Immigrant Families Manage Acculturation Stress. J. Group Psychother. Psychodr. Soc. 2017, 65, 57-73. [CrossRef]

52. Logan, A.C.; Prescott, S.L.; Haahtela, T.; Katz, D.L. The importance of the exposome and allostatic load in the planetary health paradigm. J. Physiol. Anthropol. 2018, 37, 15. [CrossRef] [PubMed]

53. Cunsolo, A.; Ellis, N.R. Ecological grief as a mental health response to climate change-related loss. Nat. Clim. Chang. 2018, 8, 275-281. [CrossRef]

54. Mack, J. Inventing a psychology of our relationship to the earth. In Psychology and Social Responsibility: Facing Global Challenges; Staub, S., Green, P., Eds.; NYU Press: New York, NY, USA, 1992; pp. 237-247.

55. Butler, C.D. Sounding the Alarm: Health in the Anthropocene. Int. J. Environ. Res. Public Health 2016, 13, 665. [CrossRef] [PubMed]

56. Logan, A.C.; Prescott, S.L. Astrofood, priorities and pandemics: Reflections of an ultra-processed breakfast program and contemporary dysbiotic drift. Challenges 2017, 8, 24. [CrossRef]

57. Potvin, L.; Jones, C.M. Twenty-five years after the Ottawa Charter: The critical role of health promotion for public health. Can. J. Public Health 2011, 102, 244-248. [PubMed]

58. Planetary Health Infographic: Safeguarding Human Health in the Anthropocene Epoch. Report of The Rockefeller Foundation-Lancet Commission on Planetary Health. Available online: https:/ /www.thelancet. com/infographics/planetary-health (accessed on 24 July 2018).

59. Food and Agriculture Organization of the United Nations (FAO). The State of Food Security and Nutrition in the World 2017. Available online: http:/ / www.fao.org/3/a-I7695e.pdf. (accessed on 24 July 2018).

60. World Health Organization (WHO) and the United Nations Children's Fund (UNICEF). Progress on Drinking Water, Sanitation and Hygiene, July 2017. Available online: http://www.who.int/mediacentre/news/ releases / 2017/launch-version-report-jmp-water-sanitation-hygiene.pdf (accessed on 24 July 2018).

61. Davies, G.I.; McIver, L.; Kim, Y.; Hashizume, M.; Iddings, S.; Chan, V. Water-borne diseases and extreme weather events in Cambodia: Review of impacts and implications of climate change. Int. J. Environ. Res. Public Health 2014, 12, 191-213. [CrossRef] [PubMed]

62. Albrecht, G.; Sartore, G.M.; Connor, L.; Higginbotham, N.; Freeman, S.; Kelly, B.; Stain, H.; Tonna, A.; Pollard, G. Solastalgia: The distress caused by environmental change. Australas. Psychiatry 2007, 15, S95-S98. [CrossRef] [PubMed]

63. Booth, A.L.; Jacobs, H.M. Environmental Consciousness-Native American Worldviews and Sustainable Natural Resource Management: An Annotated Bibliography. In CPL Bibliography, No. 214 Chicago; Council of Planning Librarians: Monticello, IL, USA, 1988.

64. Logan, A.C. Dysbiotic drift: Mental health, environmental grey space, and microbiota. J. Physiol. Anthropol. 2015, 34, 23. [CrossRef] [PubMed]

65. Shepherd, S.; Lima, M.A.P.; Oliveira, E.E.; Sharkh, S.M.; Jackson, C.W.; Newland, P.L. Extremely Low Frequency Electromagnetic Fields impair the Cognitive and Motor Abilities of Honey Bees. Sci. Rep. 2018, 8, 7932. [CrossRef] [PubMed]

66. Balmori, A. Anthropogenic radiofrequency electromagnetic fields as an emerging threat to wildlife orientation. Sci. Total Environ. 2015, 518-519, 58-60. [CrossRef] [PubMed]

67. Arshad, S.H.; Karmaus, W.; Zhang, H.; Holloway, J.W. Multigenerational cohorts in patients with asthma and allergy. J. Allergy Clin. Immunol. 2017, 139, 415-421. [CrossRef] [PubMed]

68. Miska, E.A.; Ferguson-Smith, A.C. Transgenerational inheritance: Models and mechanisms of non-DNA sequence-based inheritance. Science 2016, 354, 59-63. [CrossRef] [PubMed]

69. Rothstein, M.A.; Harrell, H.L.; Marchant, G.E. Transgenerational epigenetics and environmental justice. Environ. Epigenet. 2017, 3, dvx011. [CrossRef] [PubMed]

70. Prescott, S.L.; Logan, A.C. Transforming Life: A Broad View of the Developmental Origins of Health and Disease Concept from an Ecological Justice Perspective. Int. J. Environ. Res. Public Health 2016, 13, 1075. [CrossRef] [PubMed] 
71. Capaldi, C.A.; Passmore, H.A.; Ryo, I.; Chistopolskaya, K.A.; Vowinckel, J.; Nikolaev, E.L.; Semikin, G.I. Engaging with natural beauty may be related to well-being because it connects people to nature: Evidence from three cultures. Ecopsychology 2017, 9, 199-211. [CrossRef]

72. Sobko, T.; Tse, M.; Kaplan, M. A randomized controlled trial for families with preschool children—Promoting healthy eating and active playtime by connecting to nature. BMC Public Health 2016, 16, 505. [CrossRef] [PubMed]

73. Lindsay, E.K.; Young, S.; Smyth, J.M.; Brown, K.W.; Creswell, J.D. Acceptance lowers stress reactivity: Dismantling mindfulness training in a randomized controlled trial. Psychoneuroendocrinology 2018, 87, 63-73. [CrossRef] [PubMed]

74. Stellar, J.E.; John-Henderson, N.; Anderson, C.L.; Gordon, A.M.; McNeil, G.D.; Keltner, D. Positive affect and markers of inflammation: Discrete positive emotions predict lower levels of inflammatory cytokines. Emotion 2015, 15, 129-133. [CrossRef] [PubMed]

75. Prescott, S.L.; Kozyrskyj, A.; Logan, A.C.; Campbell, D. Proceedings of the 7th Annual inVIVO Planetary Health Congress. Challenges 2018, in press.

76. Daisley, B.A.; Trinder, M.; McDowell, T.W.; Welle, H.; Dube, J.S.; Ali, S.N.; Leong, H.S.; Sumarah, M.W.; Reid, G. Neonicotinoid-induced pathogen susceptibility is mitigated by Lactobacillus plantarum immune stimulation in a Drosophila melanogaster model. Sci. Rep. 2017, 7, 2703. [CrossRef] [PubMed]

77. Reid, G.; Nduti, N.; Sybesma, W.; Kort, R.; Kollmann, T.R.; Adam, R.; Boga, H.; Brown, E.M.; Einerhand, A.; El-Nezami, H.; et al. Harnessing microbiome and probiotic research in sub-Saharan Africa: Recommendations from an African workshop. Microbiome 2014, 2, 12. [CrossRef] [PubMed]

78. Haahtela, T.; Valovirta, E.; Bousquet, J.; Makela, M.; the Allergy Programme Steering Group. The Finnish Allergy Programme 2008-2018 works. Available online: http:/ / erj.ersjournals.com/content/49/6/1700470 (accessed on 24 July 2018).

79. Haahtela, T.; Hanski, I.; von Hertzen, L.; Jousilahti, P.; Laatikainen, T.; Makela, M.; Puska, P.; Reijula, K.; Saarinen, K.; Vartiainen, E.; et al. "Nature step" to prevent noncommunicable inflammatory disease. Duodecim 2017, 133, 19-26. [PubMed]

80. Roberts, C.M.; Kane, R.T.; Rooney, R.M.; Pintabona, Y.; Baughman, N.; Hassan, S.; Cross, D.; Zubrick, S.R.; Silburn, S.R. Efficacy of the Aussie Optimism Program: Promoting Pro-social Behavior and Preventing Suicidality in Primary School Students. A Randomised-Controlled Trial. Front. Psychol. 2017, 8, 1392. [CrossRef] [PubMed]

81. Lowry, C.A.; Smith, D.G.; Siebler, P.H.; Schmidt, D.; Stamper, C.E.; Hassell, J.E., Jr.; Yamashita, P.S.; Fox, J.H.; Reber, S.O.; Brenner, L.A.; et al. The Microbiota, Immunoregulation, and Mental Health: Implications for Public Health. Curr. Environ. Health Rep. 2016, 3, 270-286. [CrossRef] [PubMed]

82. Bobel, T.S.; Hackl, S.B.; Langgartner, D.; Jarczok, M.N.; Rohleder, N.; Rook, G.A.; Lowry, C.A.; Gundel, H.; Waller, C.; Reber, S.O. Less Immune Activation Following Social Stress in Rural vs. Urban Participants Raised with Regular or No Animal Contact, Respectively. Available online: http:/ / www.pnas.org/content/ early/2018/04/24/1719866115 (accessed on 25 July 2018).

83. Frank, M.G.; Fonken, L.K.; Dolzani, S.D.; Annis, J.L.; Siebler, P.H.; Schmidt, D.; Watkins, L.R.; Maier, S.F.; Lowry, C.A. Immunization with Mycobacterium vaccae induces an anti-inflammatory milieu in the CNS: Attenuation of stress-induced microglial priming, alarmins and anxiety-like behavior. Brain Behav. Immun. 2018. [CrossRef] [PubMed]

84. Bharwani, A.; Mian, M.F.; Surette, M.G.; Bienenstock, J.; Forsythe, P. Oral treatment with Lactobacillus rhamnosus attenuates behavioural deficits and immune changes in chronic social stress. BMC Med. 2017, 15, 7. [CrossRef] [PubMed]

85. Slykerman, R.F.; Hood, F.; Wickens, K.; Thompson, J.M.D.; Barthow, C.; Murphy, R.; Kang, J.; Rowden, J.; Stone, P.; Crane, J.; et al. Effect of Lactobacillus rhamnosus HN001 in Pregnancy on Postpartum Symptoms of Depression and Anxiety: A Randomised Double-blind Placebo-controlled Trial. EBioMedicine 2017, 24, 159-165. [CrossRef] [PubMed]

86. Batal, M.; Johnson-Down, L.; Moubarac, J.C.; Ing, A.; Fediuk, K.; Sadik, T.; Chan, H.M.; Willows, N. Sociodemographic associations of the dietary proportion of ultra-processed foods in First Nations peoples in the Canadian provinces of British Columbia, Manitoba, Alberta and Ontario. Int. J. Food Sci. Nutr. 2017, 69, 1-9. [CrossRef] [PubMed] 
87. De Vries, E.; Van Schrojenstein Lantman, M.; Hoebregts, V.; Mackus, M.; Garssen, J.; Verster, J.C.; Scholey, A. Mediterranean diet and mood. Eur. Neuropsychpharm 2017, 27, S879-S880. [CrossRef]

88. Slow Food Foundation for Biodiversity. Okanagan Sockeye Salmon, A Primary Food Mainstay of the Syilx Peoples. Available online: https://www.fondazioneslowfood.com/en/slow-food-presidia/okanagansockeye-salmon/ (accessed on 25 July 2018).

89. Torngat Wildlife Plants and Fisheries Secretariat, Happy Valley-Goose Bay. Available online: https://www. torngatsecretariat.ca/home/about.htm (accessed on 25 July 2018).

90. Dettling, J.R. The amazing futurephone. Sci. Dig. 1982, 92, 88.

91. Bugliarello, G. A global network emerges. Sci. Dig. 1984, 92, 49.

92. Alexander, C.P. The new economy. Time 1983, 121, 62.

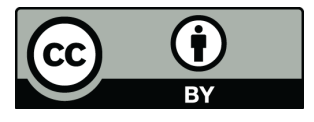

(C) 2018 by the authors. Licensee MDPI, Basel, Switzerland. This article is an open access article distributed under the terms and conditions of the Creative Commons Attribution (CC BY) license (http:/ / creativecommons.org/licenses/by/4.0/). 